\title{
A NEW METHOD FOR THE MEASUREMENT OF PHOTOGRAPHIC FILTER FACTORS
}

\author{
By Raymond Davis
}

\begin{abstract}
A new method is described whereby the filter factors for orthochromatic and panchromatic plates with various filters may be determined with apparatus using a source of light which is corrected in its spectral energy distribution to closely approximate that of average noon sunlight.

The apparatus is essentially a single light source photometer in which two beams one from either side of the lamp, are reflected so that they fall side by side on the photographic plate which is used in conjunction with the filter. In the path of one of these beams the filter is inserted, consequently weakening the light in that beam. The lamp, being movable between two of the reflectors, is shifted toward the filter, thus increasing the intensity of the beam on the filter side and diminishing it on the other. Successive exposures are thus made at different lamp positions, so chosen that some fall on one side of the photographic match and some on the other. After development the differences in density between each pair of exposures is measured, and the position of a photographic match obtained therefrom by plotting these differences against the scale of the instrument. Knowing the length of the path of the two beams of light the law of inverse squares is applied to calculate the filter factor.
\end{abstract}

\section{CONTENTS}

Page

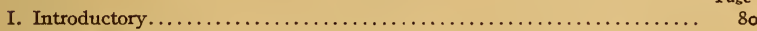

II. Apparatus and method of procedure $\ldots \ldots \ldots \ldots \ldots \ldots \ldots \ldots \ldots \ldots \ldots$

1. Description of instrument. . . . . . .

2. Experimental procedure.................... 8 r

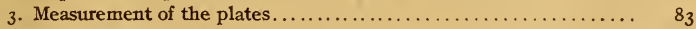

III. Necessary precautions. . . . . . . . . . . . . . . . . . . . . 84

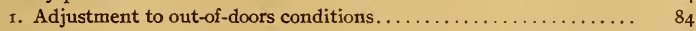

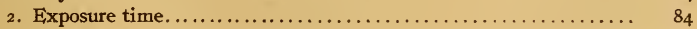

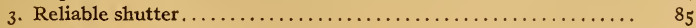

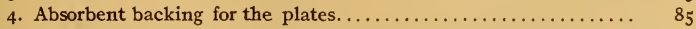

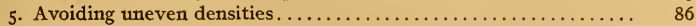

IV. Precision attainable $\ldots \ldots \ldots \ldots \ldots \ldots \ldots \ldots \ldots \ldots \ldots \ldots \ldots \ldots \ldots \ldots$

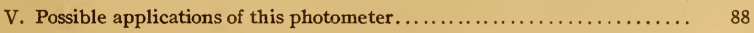

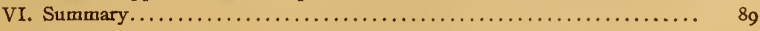
$24634^{\circ}-21$ 


\section{INTRODUCTORY}

Orthochromatic and panchromatic plates are almost always used with photographic filters (colored screens of glass or gelatin) to control the color and intensity of the light falling on the photographic plates. Since the use of a filter decreases the intensity of certain colors on the plate the photographic exposure through a filter will be greater than that required for the same plate used without a filter.

A filter factor is the ratio of the exposure required with a given filter to the exposure without the filter; hence, to obtain the proper time of exposure when using the filter, the proper time of exposure without the filter should be multiplied by the filter factor.

Heretofore, so far as the author knows, filter factors have been determined by either of two methods. First, the method of trial and error; and second, the measurement, in some form of sensitometer, of plate speeds without and with the given filter. In the course of a study of the plates and films made in the United States it was desired to measure, among other things, the filter factors of all orthochromatic and panchromatic emulsions for a number of different filters. A method was thereupon devised with which it has been possible to measure filter factors with an accuracy equal to or better than that attained in careful speed measurements, and yet with much less effort.

\section{APPARATUS AND METHOD OF PROCEDURE}

\section{DESCRIPTION OF APPARATUS}

The apparatus, Fig. $\mathrm{I}$, is as follows: Light from the two sides of a standard metal filament lamp $L$ is reflected by similar reflectors $M_{1}, M_{2}, M_{3}, M_{4}$, and by similar prisms, $P_{1}$ and $P_{2}$, so that the two beams fall side by side on the photographic plate $E$, the filter factors of which are to be determined. In front of the plate $E$ is a simple shutter. The source of light $L$ is movable along the line joining $M_{1}$ and $M_{3}$. At $F$, between $M_{3}$ and $M_{4}$, supports to hold the filters are inserted.

The lamp initially at the position $a$ will give two beams of equal intensity at the photographic plate if the distances traversed by them are the same and if identical optical conditions of reflection and absorption obtain for the various media through which they pass. If a filter be inserted in one path, the intensity of that beam is decreased, so in order to make the beams of the same intensity 
it is necessary to shift the lamp toward the filter, position $b$, thus shortening that path and increasing the other. In the case without a filter equal illumination is obtained with equal paths; the ratio by which the filter decreases the intensity of the light is equal to the square of the length of the path without the filter, divided by the square of the length of the path which contains the filter. This ratio is the filter factor sought.
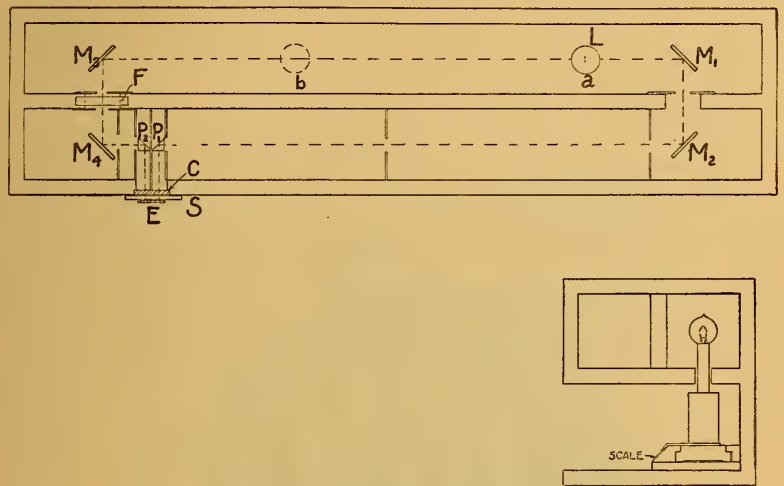

FIG. I.-Plan and sectional view of filter-factor apparatus

\section{EXPERIMENTAL PROCEDURE}

In practice the point of balance is determined by making a series of exposures on the plate with the lamp at such distances that some are distributed on one side of the point of balance and some on the other. The plate is developed and fixed, and the density differences corresponding to the given positions of the lamp are measured on a polarization photometer. These differences are then plotted (as shown in Fig. 2) against the position of the lamp-positive or negative according to whether the setting made the lamp distance too large or too small-and the setting for a balance located where the smooth curve crosses the position axis.

In the plot given the scale zero is taken as the point of balance without a filter. With the $K_{1}$ filter, the curve is found to cross the instrument scale at $27 \mathrm{~cm}$. Hence, 27.0 is the distance in centimeters of the new point of balance with the $K_{1}$ filter from the point of balance of the instrument without the filter. 
Knowing the length of the paths of light to the point of balance without a filter and the distance of the new point of balance with the filter from the position of equilibrium without the filter, the law of inverse squares can be applied to calculate the filter factor. For example:

Length of path of each beam of light when both beams give equal exposure without the filter $=100 \mathrm{~cm}$;

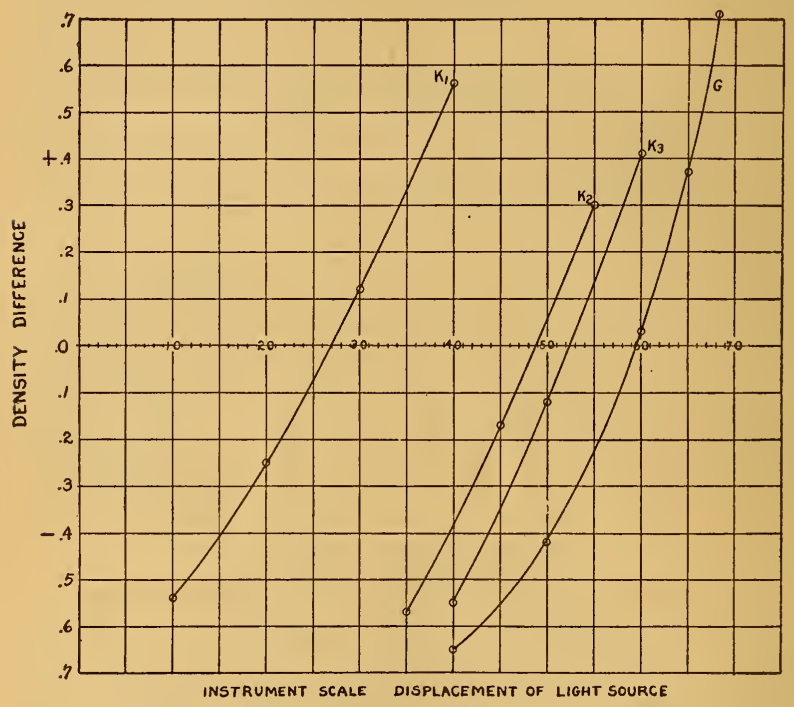

FIG. 2.-Typical curves of density differences, showing the method of plotting

Point of balance with the $K_{1}$ filter (that is, distance by which one of the beams was lengthened and the other shortened) $=27.0 \mathrm{~cm}$;

Hence, Length of path on one side $=100+27.0=127.0 \mathrm{~cm}$;

Length of path on other side $=100-27.0=73.0 \mathrm{~cm}$; Applying the law of inverse squares:

$$
\text { Filter factor sought }=\frac{127^{2}}{73^{2}}=3.03 \text {. }
$$

The apparatus as constructed has each path about I $\mathrm{m}$ long when the lamp is in the zero position, and the lamp has a move- 
Scientific Papers of the Bureau of Standards, Vol. 17

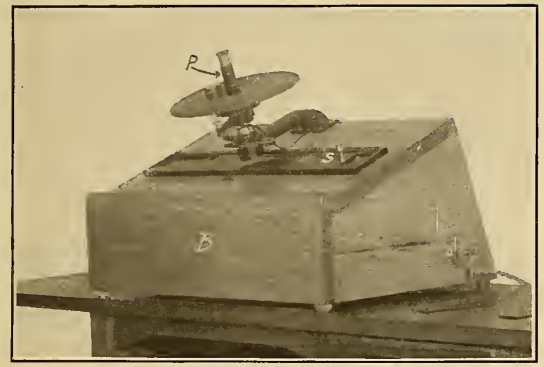

FIG. 3.-Photometer for measuring test plates 
Scientific Papers of the Bureau of Standards, Vol. 17

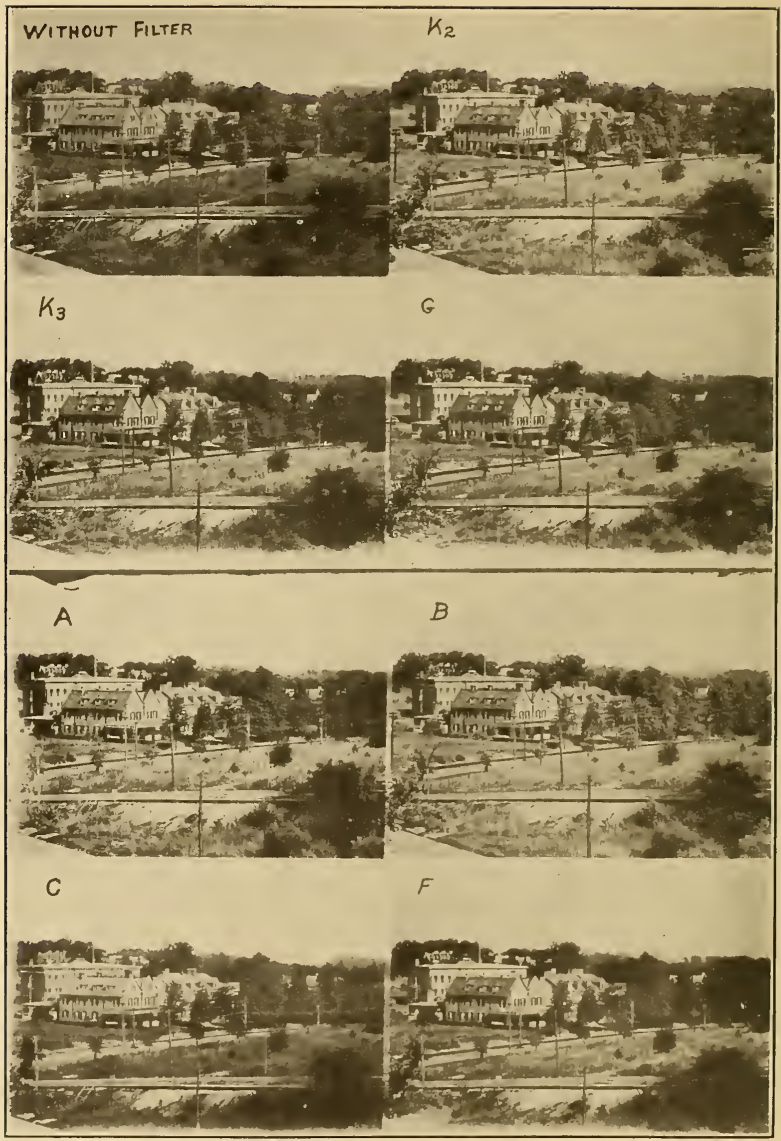

FIG. 4.-Photographs taken with and without filters

The exposure times with filters were adjusted according to the measured factors 
ment of about $69 \mathrm{~cm}$, so that the range of factors which can be measured is from I to 30 . The filters used must be larger than one-half inch square. The strips of the photographic plate tested are $I / 8$ by 5 inches, permitting two filter factors to be measured conveniently on each.

In measuring filter factors, four or five settings (one exposure at each setting) are made with each filter as described in Section II, 2. Since nine exposures can be made on each test plate, a single plate serves to test two filters.

The trouble and loss of time required to make preliminary tests were avoided by preparing tables, such as Table $\mathrm{I}$, which give the range of settings of the lamp suitable to the color sensitivity of the various types and brands of plates and filters. For example, filter $K_{1}$ with a panchromatic plate was tested for the scale positions $10,20,30$, and 40 . This procedure is practicable because the variation in color sensitivity with emulsions of the same brand is as a rule not nearly so large as the differences in the same type of emulsions of different manufacture.

TABLE 1.-Range of Settings for Class C Plates PANCHROMATIC PLATES

\begin{tabular}{|c|c|c|}
\hline Filter & Factor range & Use scale settings \\
\hline$K_{1}$. & 1.5 to 5.5 & $10-20-30-40$ \\
\hline$K_{2} \ldots$ & 2.8 to 12.3 & $25-35-45-55$ \\
\hline$K_{3} \ldots \ldots \ldots \ldots \ldots$ & 5.5 to 23 & $40-50-60-65$ \\
\hline$G \ldots \ldots \ldots \ldots \ldots \ldots \ldots$ & 5.5 to 30 & $40-50-60-65-68.2$ \\
\hline A...... & 9. 3 to 30 & $50-60-65-68.2$ \\
\hline 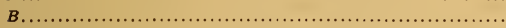 & 5.5 to 23 & $40-50-60-65$ \\
\hline C.......................... & 5.5 to 23 & $40-50-60-65$ \\
\hline 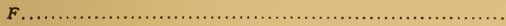 & 9.3 to 30 & $50-55-60-65-68.2$ \\
\hline
\end{tabular}

ORTHOCHROMATIC PLATES

\begin{tabular}{|c|c|c|}
\hline$K, \ldots \ldots \ldots \ldots \ldots \ldots \ldots$ & 1.5 to 5.5 & $10-20-30-40$ \\
\hline 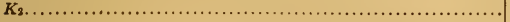 & 2.8 to 12.3 & $25-35-45-55$ \\
\hline 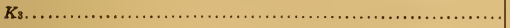 & 5.5 to 23 & $40-50-60-65$ \\
\hline 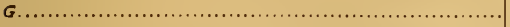 & 5.5 to 30 & $40-50-60-65-68.2$ \\
\hline
\end{tabular}

\section{MEASURING THE TEST PLATES}

The photometric apparatus used to measure the density differences was constructed primarily for measuring the density of the test plates exposed in the sensitometer. In this the photometer $P$, Fig. 3 , is a Martens polarization instrument. The illumination in box $B$ is diffuse, the light entering the photometer being reflected 
from a ground opal glass plate, surrounded on four sides with ground glass, outside of which are placed electric lamps symmetrically arranged to give uniform illumination. The test strip is placed in the sliding holder $S$, which by means of stops brings the center of the two squares under the respective apertures of the photometer. The angular readings of the polarization instru. ment are reduced to densities by means of a table computed for the purpose.

\section{NECESSARY PRECAUTIONS}

\section{ADJUSTMENT TO OUT-OF-DOORS CONDITIONS}

In order to have filter factors which can be used out of doors, it is necessary to modify the distribution of spectral energy of the metal-filament lamp. This is accomplished by placing in both beams a suitable screen (at $C$, Fig. I). It is also necessary to run the lamp at a constant and specified current so as to keep its spectral distribution constant. This combination of lamp and filter gives a close approximation in spectral energy distribution to that of average noon sunlight at Washington and is identical with that used as the standard light source of the Bureau of Standards sensitometer. That the apparatus furnishes satisfactory results in this respect is shown by the illustrations in Fig. 4, in which the calculated exposures used ran as high as 24 times that without the filter. As can be seen, the exposures, which were proportional to the filter factors as measured, were made on two plates, the two being developed together for the same length of time and printed simultaneously on one sheet of paper. The filters used (Wratten) and their factors for the plate used (Wratten M) were as follows:

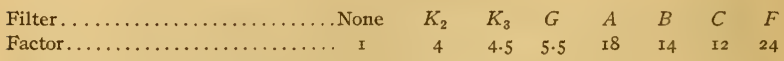

\section{THE EXPOSURE TIME}

The exposure tinue is of considerable importance and should be such that the operation is confined to the straight-line portion of the characteristic ( $H$ and $D$ ) curve for the plate tested. With a few exceptions, this straight-line portion is sufficiently long so that difficulties arising from this cause are not to be expected. Table 2 shows the effect of using exposures longer than the straightline part. For this series of tests a thinly coated plate having a 
scale of only i 5 was selected and from it two test pieces cut and exposed as indicated-one plate with the light source on one side of the position of photographic match (scale 35) and the other with it on the opposite side (scale 45).

Thus, compared with a plate in the filterless arm, the plate for position 45 had an excess density (density difference +o.15, for exposure $1 / 2$ ); while the other plate for position 35 had a less density $(-0.03)$. Each of these pairs of densities was used as in Fig. 2 for determining the position of match, and therefrom the corresponding filter factor in column 4 calculated. Nine exposures varying in time from one-half to four seconds were thus made on each plate. They show that a three-fourth-second exposure has carried the effect on the undimmed part beyond the straight-line portion of the characteristic curve.

TABLE 2.-Effect of Overexposure on the Calculated Filter Factor

\begin{tabular}{|c|c|c|c|}
\hline \multicolumn{2}{|c|}{ Position of lamp on scale } & $\begin{array}{c}\text { Approzimate } \\
\text { exposure }\end{array}$ & $\begin{array}{c}\text { Filter factor } \\
\text { (calc.) }\end{array}$ \\
\cline { 1 - 3 } 35 & 45 & ISeconds & \\
\cline { 1 - 2 }-0.03 & +.15 & $1 / 2$ & 3.00 \\
-.03 & +.15 & $1 / 2$ & 3.00 \\
-.03 & +.14 & $1 / 2$ & 3.05 \\
-.04 & +.15 & $1 / 2$ & 3.08 \\
-.05 & +.13 & $3 / 4$ & 3.20 \\
-.09 & +.10 & 1 & 3.40 \\
-.12 & +.08 & 2 & 3.70 \\
-.10 & +.05 & 3 & 3.76 \\
-.12 & +.02 & 4 & 4.25 \\
\hline
\end{tabular}

\section{RELIABLE SHUTTER}

For measurements of this kind the shutter should be mechanically operated and so arranged that the timing can be adjusted to suit the sensitiveness of the material to be tested. It should also, of course, be of such construction that the exposure time is repeated with moderate precision for all the exposures of a given set, else false density differences may result.

\section{ABSORBENT BACKING FOR THE PLATES}

It is necessary to back all plates used for sensitometric tests with some light-absorbing medium to prevent halation. This backing to be effective must be in optical contact with and of about 
the same refractive index as the glass plate. In all of our sensitometric work black shellac has been used for this purpose. When properly made and applied, it is very effective, but is more difficult to remove than the burnt-sugar backing usually recommended. The chief advantage of the shellac mixture is that it dries very quickly and does not come off or injure the developing and fixing solutions. It may be removed by scraping with the edge of a rectangular block of wood. The plates should be exposed and developed soon after the backing has become dry because it is much easier to remove it then than if applied several hours before developing.

\section{AVOIDING UNEVEN DENSITIES}

The condition of the surface of the test plate when placed on the racks to dry is also important. Besides being sponged off with wet absorbent cotton to remove sediment accumulated from the solutions and wash water, all drops of water must be removed from the surface of the film, otherwise the densities will be uneven, due to the unequal rate of drying of the different parts.

\section{PRECISION ATTAINABLE}

High precision can not be obtained with any apparatus where the results depend on the density of the silver deposit on commercial photographic plates and films. This is clearly shown by the results of a series of tests recorded in Table 3 . For this, six 5 by 7 plates were selected and numbered i to 6 , inclusive. Plates I, 2, and 3 were of the same manufacture-the second, seventh, and last plate in a package-the rest of different manufacture. Each plate was cut into five standard-size test pieces, four of which were selected for test. Each strip furnished two determinations for the filter factor-four exposures being used in each case to locate the position of photometric balance. Thus the vertical columns in the table give the variation in the factor over the same plate, and its mean value; the first three columns show how it varies with different plates of the same manufacture; the first five, how the factor for the same filter $\left(K_{3}\right)$ varies with the plates of different manufacture; while column 6 is added merely to show the variation over a single plate for a $G$ filter. 
TABLE 3.-Showing Filter Factor Variations

\begin{tabular}{|c|c|c|c|c|c|c|}
\hline Plate... & No. 1 & No. 2 & No. 3 & No. 4 & No. 5 & No. 6 \\
\hline Fllters. & $K_{3}$ & $K_{3}$ & $K_{3}$ & $K_{3}$ & $K_{3}$ & G \\
\hline \multirow{8}{*}{ Filter factors.... } & ( 13.75 & 13.20 & 13.60 & 5.18 & 4.80 & 27.0 \\
\hline & 13.92 & 13.41 & 13.68 & 5.41 & 4.85 & 27.0 \\
\hline & 14.00 & 13. 35 & 13.82 & 5.37 & 4.82 & 26.6 \\
\hline & 14. 18 & 13.95 & 14.00 & 5.12 & 4.76 & 26.6 \\
\hline & 13.92 & 13.82 & 14. 10 & 5.41 & 4.85 & 26.6 \\
\hline & 13.68 & 14.10 & 13.65 & 5.41 & 4.82 & 27.0 \\
\hline & 14.10 & 13.41 & 14.80 & 5.45 & (a) & 26.4 \\
\hline & 14.42 & 13.60 & 14.60 & 5.37 & (a) & 27.4 \\
\hline Average.. & 13.99 & 13.60 & 14.03 & 5.34 & 4.82 & 26.8 \\
\hline Max. dev., per cent. & 3.1 & 3.7 & 5.5 & 4.1 & 1.2 & 2.2 \\
\hline
\end{tabular}

a Defective plates.

The maximum variation from the mean for any single plate, I.2 per cent to 5.5 per cent, may seem large, but it is after all very satisfactory when compared with the variation in the sensitiveness of the commercial materials.

The following experiments demonstrate the corresponding density variation of different parts of single plates. Two 5 by 7 inch plates of different makes were placed behind a grid consisting of five opaque black bars separated by their own width-each bar half as wide as the standard test plate. Each plate was first given a timed exposure to the regular source (compensated to sunlight distribution) placed at $3 \mathrm{~m}$ distance. The plate was then shifted across the grid so that the parts just exposed were covered by the bars and the parts unexposed uncovered. With a color filter introduced in the light path, in one case a $K_{3}$ and the other a $G$ filter, a second exposure was then made. For the $K_{3}$ filter the second exposure was adjusted by the filter factor to give equal density, while for the $G$ filter a somewhat lower density was purposely sought. The two plates were developed together to a moderate contrast, and after fixing, washing, and drying were cut into standard size test strips, each test strip having a pair of exposures run ning the full length, one the result of the exposure with the color filter and one without. The difference in density, measured at intervals of one-half inch along the length of the strip-given in Tables 4 and 5-shows the resulting variations in density differences. 
TABLE 4.-Variation in Density Over a Single Plate- $\mathbf{K}_{3}$ Filter

\begin{tabular}{|c|c|c|c|c|}
\hline $\begin{array}{l}\text { Strip } \\
\text { No. } 1\end{array}$ & $\begin{array}{l}\text { Strip } \\
\text { No. } 2\end{array}$ & $\begin{array}{l}\text { Strip } \\
\text { No. } 3\end{array}$ & $\begin{array}{l}\text { Strip } \\
\text { No. } 4\end{array}$ & $\begin{array}{l}\text { Strip } \\
\text { No. } 5\end{array}$ \\
\hline-0.01 & -0.02 & +0.01 & -0.02 & -0.01 \\
\hline+.01 & -.01 & -.01 & -.01 & -.01 \\
\hline+.01 & +.01 & -.01 & +.01 & -.01 \\
\hline+.03 & .00 & .00 & +.01 & +.01 \\
\hline .00 & +.01 & -.01 & -.01 & +.03 \\
\hline 0.00 & -0.01 & -0.01 & 0.00 & +0.04 \\
\hline+.01 & .00 & -.02 & -.01 & +03 \\
\hline .00 & -.01 & +.01 & -.01 & +.02 \\
\hline-.03 & -.01 & +.02 & -.03 & +01 \\
\hline
\end{tabular}

TABLE 5.-Variation in Density Over Another Plate-G Filter

\begin{tabular}{|c|c|c|c|c|}
\hline $\begin{array}{c}\text { Strip } \\
\text { No.1 }\end{array}$ & $\begin{array}{c}\text { Strip } \\
\text { No.2 }\end{array}$ & $\begin{array}{c}\text { Strip } \\
\text { No. 3 }\end{array}$ & $\begin{array}{c}\text { Strip } \\
\text { No.4 }\end{array}$ & $\begin{array}{c}\text { Strip } \\
\text { No.5 }\end{array}$ \\
\cline { 1 - 3 }-0.17 & -0.13 & -0.15 & -0.15 & -0.16 \\
-.12 & -.15 & -.17 & -.15 & -.12 \\
-.16 & -.15 & -.15 & -.14 & -.11 \\
-.13 & -.12 & -.14 & -.15 & -.16 \\
-.11 & -.14 & -.14 & -.13 & -.08 \\
-0.09 & -0.14 & -0.12 & -0.14 & -0.08 \\
-.09 & -.12 & -.10 & -.09 & -.09 \\
-.09 & -.12 & -.11 & -.13 & -.09 \\
-.07 & -.12 & -.09 & -.09 & -.11 \\
\hline
\end{tabular}

Table 4 shows, for one type of plate and filter, a range of density differences from +0.04 to -0.03 , that is of 0.07 ; while Table 5 shows, for another plate and filter, a range from -0.07 to -0.17 , that is o.ro. It should be added that the density differences recorded in Table 4 were proved to be real by setting the photometer for zero difference and observing that the match was thereby destroyed. Furthermore, it was observed that if the photometer were set for a match at a fixed place on the test plate, the match was destroyed when the test plate was moved to another position. It is therefore obvious that the method of testing is distinctly more reliable than the emulsion is uniform.

\section{OTHER POSSIBLE APPLICATIONS OF THE PHOTOGRAPHIC PHOTOMETER}

By replacing the filter under test with sectored wheels the intermittency effect in photographic exposures, with light sources of different intensity and different intermittency, can readily be investigated. 
The apparatus could be modified so as to measure the relative energy in different parts of the spectrum of two light sources provided suitable monochromatic filters were at hand. This method would be specially valuable where comparisons in the blue end of the spectrum are of importance, such as perhaps in the effect of humidity, etc., in the study of the variation of flame standards as compared with electric standards. Such information would be of special value in the application of flame standards for sensitometry.

\section{SUMMARY}

A new method is described whereby the filter factors for orthochromatic and panchromatic plates with various filters may be determined with apparatus using a single source of light. The energy distribution of the lamp is corrected to closely approximate that of average noon sunlight, so that the values obtained are applicable in actual practice.

The test procedure is described, and an example given to illustrate the method of calculating the factor.

Some of the most important precautions necessary for accurate work are enumerated.

Experimental evidence is given to show that the accuracy of the instrument is distinctly greater than the emulsions are uniform.

Suggestions as to the possible applicability of the apparatus to other problems are made.

WASHINGTON, July 31, 1920. 